\title{
Arterial dilator function in athletes: present and future perspectives
}

\author{
David Montero * \\ Zurich Center for Integrative Human Physiology, Institute of Physiology, University of Zurich, Zurich, Switzerland
}

Keywords: vascular function, conduit artery, resistance artery, blood flow distribution, athletes

\section{Introduction}

Although it is well established that exercise training conditions the vasculature (Joyner and Green, 2009), the status of arterial function in long-term trained subjects (i.e., athletes, ATH) has been recently disputed (Green, 2013; Montero et al., 2013). The controversy arose as to whether vasodilator function was enhanced in ATH compared with untrained healthy peers (Green et al., 2013). This contention was justified by the conflicting report of decreased (Green et al., 2011; Phillips et al., 2011) and normal (Franzoni et al., 2005b; Moe et al., 2005; Naylor et al., 2006; Ballard et al., 2008; Rognmo et al., 2008; Nualnim et al., 2011; Phillips et al., 2011; Rowley et al., 2012; Agrotou et al., 2013; Green et al., 2013) but also increased (Jensen-Urstad et al., 1999; Rywik et al., 1999; Rinder et al., 2000; Franzoni et al., 2005b; Kasikcioglu et al., 2005; Rickenlund

OPEN ACCESS

Edited by:

Antonio Colantuoni

Physiology at the International School for Advanced Studies (SISSA/ISAS),

Italy

Reviewed by:

Pasquale Pagliaro,

Università di Torino, Italy Paolo Mondola

Università degli Studi di Napoli

Federico II" ", Italy

*Correspondence: David Montero, david.montero.barri@gmail.com

Specialty section:

This article was submitted to

Vascular Physiology,

a section of the journal

Frontiers in Physiology

Received: 03 March 2015 Accepted: 06 May 2015 Published: 19 May 2015

Citation:

Montero D (2015) Arterial dilator function in athletes: present and future perspectives. Front. Physiol. 6:163. doi: 10.3389/fphys.2015.00163 et al., 2005; Tanriverdi et al., 2005; Galetta et al., 2006; Hagmar et al., 2006; Walther et al., 2008; Florescu et al., 2010; Nualnim et al., 2011; Welsch et al., 2013) flow-mediated dilation (FMD), a common index of conduit artery dilator function, in ATH vs. age-matched controls. Likewise, the evidence on resistance artery dilator function was apparently heterogeneous (Green et al., 2012). Presumably, differences in methodology, study population and the small sample size of previous reports, among others, may have contributed to cloud the status of arterial function in ATH, leading to wide speculation (Green, 2013; Montero et al., 2013). What follows is a brief viewpoint on the state-of-the-art including comprehensive meta-analytic data spanning through macro- and microvascular dilator function in primarily endurance-trained ATH, as well as an insight in to next challenges to the field.

\section{Athlete's Artery: A Superior Functional Phenotype}

Over the inconsistent results of single studies, pooled evidence demonstrates, in a paradoxical manner, an homogeneous enhanced dilator function in the smallest limb arteries and arterioles of ATH, irrespective of the age status (Montero et al., 2014b). This strongly suggests a predominant type II error in prior research, which indeed is likely common to scientific fields based on small sample size studies (Ioannidis, 2005). In addition, it is noteworthy that ATH exhibit enhanced endothelium-dependent and -independent resistance artery dilator function (Montero et al., 2014b), the latter contrasting with the passive role conventionally bestowed on the vascular smooth muscle, albeit concurring with early works (Haskell et al., 1993). Thus, it is uncertain whether the enhanced resistance artery dilator function in ATH is in accordance to improvements in smooth muscle function alone or along with endothelial function, which may not be entirely distinguished in vivo (Oltman et al., 1992). Regardless, such enhanced dilator function may correlate with increased basal vascular tone (Sugawara et al., 2007), provided that microvessel density (Lloyd et al., 2003; Zoladz et al., 2005), but not basal peripheral vascular conductance (Di Bello et al., 1996; Higashi et al., 1999; Carrick-Ranson et al., 2014), is increased in ATH. 
The superior phenotype of conduit arteries in ATH may be discerned in light of pooled evidence according to age (Montero et al., 2014a). Herein, brachial artery FMD and nitratemediated dilation (NMD), respectively reflecting endotheliumdependent and -independent conduit artery dilator function, are enhanced in master (mean age $>50$ years) but similar in young (mean age $<40$ years) ATH compared with agematched controls (Montero et al., 2014a). Conversely, basal brachial artery diameter is increased in young but similar in master ATH vs. age-matched controls (Montero et al., 2014a). Collectively, it can be inferred that both young and master ATH unequivocally demonstrate enhanced peak brachial diameter, since FMD and NMD techniques always characterize the response to a given dilator stimulus relative to basal artery diameter, despite differences may exist concerning the edge detection and wall tracking procedure, cuff-occlusion length/placement and time interval of diameter assessment (Thijssen et al., 2011). Moreover, FMD and NMD may be underestimated in young ATH in view of the widespread inverse correlation between these measures and basal conduit artery diameter (Thijssen et al., 2008). Likewise, the main dilator stimulus triggering FMD, i.e., endothelial shear rate, could be diminished in young ATH due to brachial enlargement (Pyke and Tschakovsky, 2007), which additionally suggests the presence of enhanced brachial endothelium-dependent dilator function in young ATH.

Of note, arterial adaptation in ATH may be regulated in a region-specific manner according to the impact of training characteristics (intensity, duration, frequency, volume, modality) on hemodynamic forces such as shear rate and pressure patterns, nitric oxide (NO) production and vessel structure (Maiorana et al., 2003; Prior et al., 2003a,b). These might fluctuate during periodized training programs and thereby modulate endothelial and smooth muscle dilator function. Furthermore, vasodilation is ultimately a function of the balance among substances and mechanisms that can induce dilation or constriction, including, but not limited to, NO, adenosine, ATP, tissue metabolites, endothelin-1, noradrenaline, inward rectifying $\mathrm{K}^{+}$ channels and reactive oxygen species (Korthuis, 2011). In this regard, endothelial dilator function in ATH has been positively associated with plasma antioxidant activity (Franzoni et al., 2004, 2005a), which is subject to diurnal variation (Hammouda et al., 2012). Therefore, the dynamic status of arterial dilator function may have compounded the variability and hence lessened the statistical power of previous studies in ATH. In addition, the majority of preceding research involved lower limbtrained ATH and assessed upper limb arterial function (Montero et al., 2014a,b). Nevertheless, the arterial dilator phenotype of ATH seems to be qualitatively identical but of higher magnitude if determined in primarily trained vs. untrained limbs (Walther et al., 2008). Taken together, the athlete's artery is distinguished by a supra-normal dilator function in resistance and (size-adjusted) conduit vessels, which facilitates conductance and thereby plausibly improves blood flow regulation.

\section{The Unknown Optimal Dilator-Constriction Balance}

The fact that peripheral vascular conductance during submaximal exercise may not be increased in ATH (Fleg et al., 1994; Carrick-Ranson et al., 2014) suggests that enhanced arterial dilator function interacts with increased arterial constrictor function and/or sympathetic constrictor drive. In this respect, increased both arterial constrictor function and sympathetic (re)activity have been observed in ATH (Furlan et al., 1993; Welsch et al., 2013). Seemingly, the antagonism between dilator and constrictor forces may be futile unless associated with a more efficient perfusion in that part of the cardiac output is diverted from tissue with low oxygen demand toward active skeletal muscle. This would result in increased oxygen extraction and reduced cardiac output/limb blood flow during submaximal exercise, as indeed have been noted at whole body (Ekblom et al., 1968) and limb (Proctor et al., 2001; Lawrenson et al., 2004) levels after endurance training and within exercising muscle in ATH (Kalliokoski et al., 2001).

At maximal exercise, an improved blood flow distribution may, at least in part, explain the increased arteriovenous oxygen difference seen in ATH (Fleg et al., 1994; Mollard et al., 2007a,b; Carrick-Ranson et al., 2014). Importantly, a suboptimal blood flow distribution cannot be compensated at maximal exercise by increasing the cardiac output since the maximal pumping capacity of the heart, and thus systemic oxygen delivery, is reached (Mortensen et al., 2005; Brink-Elfegoun et al., 2007; Calbet et al., 2007; Elliott et al., 2015). Moreover, oxygen extraction is reduced when overall limb vasodilation is experimentally enhanced during submaximal and maximal exercise (Calbet et al., 2006), which supports the necessary role of vasoconstriction in less active tissue to efficiently distribute blood flow. On the other hand, excessive vasoconstrictor activity may increase oxygen extraction in relative terms but concomitantly reduce oxygen consumption $\left(\mathrm{VO}_{2}\right)$ via lower absolute blood flow to active skeletal muscle (Heinonen et al., 2013).

Therefore, the optimal arterial function, as regards exercise performance, must contribute to maximize blood flow to active skeletal muscle and minimize blood flow to other tissues, while maintaining the required perfusion to exercise-related vital organs (heart, lungs, skin, brain). This is certainly favored by a region-specific arterial function, as evidenced by the observations that arterial constrictor function is enhanced in the upper limb after cycling training (Rakobowchuk et al., 2012), whereas arterial dilator function is increased in the lower limb but decreased in the upper limb of cyclists vs. swimmers (Walther et al., 2008). In this line, maximal $\mathrm{VO}_{2}$ during leg cycle ergometry is more closely associated with arterial dilator function determined in the lower vs. upper limb (Ridout et al., 2005). Accordingly, there must be a combination of equilibria between arterial dilator function and vasoconstriction at distinct (whole body, limb, muscle) levels that will best facilitate exercise performance. However, although major breakthroughs in the knowledge of molecular, biochemical and cellular bases of arterial dilator function during 
exercise have been witnessed (Pagliaro et al., 1999; Joyner and Wilkins, 2007; Calbet and Joyner, 2010; Hellsten et al., 2012), we are still in the early stages of studies capable of integrating them with concurrent vasoconstrictor activity (Reed et al., 2000; Tschakovsky et al., 2002; Rosenmeier et al., 2004; Mortensen et al., 2012; Heinonen et al., 2013). Undoubtedly, the journey toward understanding the complex way in that arterial function serves athletic capacity has just begun.

\section{Conclusion}

The remarkable arterial dilator capacity demonstrated by ATH is partly attributed to an enhanced response to vasodilator

\section{References}

Agrotou, S., Karatzi, K., Papamichael, C., Fatouros, I., Mitrakou, A., Zakopoulos, N., et al. (2013). Effects of chronic anaerobic training on markers of sub-clinical atherosclerosis. Hellenic J. Cardiol. 54, 178-185.

Ballard, K. D., Miller, J. J., Robinson, J. H., and Olive, J. L. (2008). Aerobic capacity and postprandial flow mediated dilation. Int. J. Exerc. Sci. 1, 163-176.

Brink-Elfegoun, T., Kaijser, L., Gustafsson, T., and Ekblom, B. (2007). Maximal oxygen uptake is not limited by a central nervous system governor. J. Appl. Physiol. (1985) 102, 781-786. doi: 10.1152/japplphysiol.0056 6.2006

Calbet, J. A., Gonzalez-Alonso, J., Helge, J. W., Sondergaard, H., Munch-Andersen, T., Boushel, R., et al. (2007). Cardiac output and leg and arm blood flow during incremental exercise to exhaustion on the cycle ergometer. J. Appl. Physiol (1985) 103, 969-978. doi: 10.1152/japplphysiol.01281.2006

Calbet, J. A., and Joyner, M. J. (2010). Disparity in regional and systemic circulatory capacities: do they affect the regulation of the circulation? Acta Physiol. (Oxf). 199, 393-406. doi: 10.1111/j.1748-1716.2010.02125.x

Calbet, J. A., Lundby, C., Sander, M., Robach, P., Saltin, B., and Boushel, R. (2006). Effects of ATP-induced leg vasodilation on VO2 peak and leg O2 extraction during maximal exercise in humans. Am. J. Physiol. Regul. Integr. Comp. Physiol. 291, R447-R453. doi: 10.1152/ajpregu.00746.2005

Carrick-Ranson, G., Hastings, J. L., Bhella, P. S., Fujimoto, N., Shibata, S., Palmer, M. D., et al. (2014). The effect of lifelong exercise dose on cardiovascular function during exercise. J. Appl. Physiol. (1985) 116, 736-745. doi: 10.1152/japplphysiol.00342.2013

Di Bello, V., Santoro, G., Talarico, L., Di Muro, C., Caputo, M. T., Giorgi, D., et al. (1996). Left ventricular function during exercise in athletes and in sedentary men. Med. Sci. Sports Exerc. 28, 190-196. doi: 10.1097/00005768-19960200000006

Ekblom, B., Astrand, P. O., Saltin, B., Stenberg, J., and Wallstrom, B. (1968). Effect of training on circulatory response to exercise. J. Appl. Physiol. 24, 518-528.

Elliott, A. D., Skowno, J., Prabhu, M., Noakes, T. D., and Ansley, L. (2015). Evidence of cardiac functional reserve upon exhaustion during incremental exercise to determine VO2max. Br. J. Sports Med. 49, 128-132. doi: 10.1136/bjsports-2012-091752

Fleg, J. L., Schulman, S. P., O'connor, F. C., Gerstenblith, G., Becker, L. C., Fortney, S., et al. (1994). Cardiovascular responses to exhaustive upright cycle exercise in highly trained older men. J. Appl. Physiol. (1985) 77, 1500-1506.

Florescu, M., Stoicescu, C., Magda, S., Petcu, I., Radu, M., Palombo, C., et al. (2010). "Supranormal" cardiac function in athletes related to better arterial and endothelial function. Echocardiography 27, 659-667. doi: 10.1111/j.15408175.2009.01121.x

Franzoni, F., Ghiadoni, L., Galetta, F., Plantinga, Y., Lubrano, V., Huang, Y., et al. (2005a). Physical activity, plasma antioxidant capacity, and endotheliumdependent vasodilation in young and older men. Am. J. Hypertens. 18, 510-516. doi: 10.1016/j.amjhyper.2004.11.006 stimuli. This is particularly observed in peripheral resistance vessels, but also in upstream conduit arteries when adjusted for lumen dimensions, which are increased in young ATH. Notwithstanding the age status, the athletic arterial phenotype is, at least in part, characterized by the enhancement of vascular smooth muscle dilator function. Yet, such enhanced dilator function seems to be region-specific and paralleled by increased vasoconstriction in order to efficiently distribute a finite cardiac output. The understanding of the interplay between arterial dilator-constrictor function and sympathetic drive at multiple hierarchical levels during exercise remains elusive and a challenge for future research in to the physiological bases of human performance.
Franzoni, F., Ghiadoni, L., Galetta, F., Plantinga, Y., Lubrano, V., Huang, Y., et al. (2005b). Physical activity, plasma antioxidant capacity, and endotheliumdependent vasodilation in young and older men. Am. J. Hypertens. 18, 510-516. doi: 10.1016/j.amjhyper.2004.11.006

Franzoni, F., Plantinga, Y., Femia, F. R., Bartolomucci, F., Gaudio, C., Regoli, F., et al. (2004). Plasma antioxidant activity and cutaneous microvascular endothelial function in athletes and sedentary controls. Biomed. Pharmacother. 58, 432-436. doi: 10.1016/S0753-3322(04)00115-5

Furlan, R., Piazza, S., Dell'Orto, S., Gentile, E., Cerutti, S., Pagani, M., et al. (1993). Early and late effects of exercise and athletic training on neural mechanisms controlling heart rate. Cardiovasc. Res. 27, 482-488. doi: 10.1093/cvr/27.3.482

Galetta, F., Franzoni, F., Virdis, A., Ghiadoni, L., Taddei, S., Salvetti, A., et al. (2006). Endothelium-dependent vasodilation and carotid artery wall remodeling in athletes and sedentary subjects. Atherosclerosis 186, 184-192. doi: 10.1016/j.atherosclerosis.2005.07.013

Green, D. (2013). Enhanced conduit artery flow-mediated dilation in elite athletes: false or reality? Author reply. Med. Sci. Sports Exerc. 45, 1220. doi: 10.1249/MSS.0b013e31828d6016

Green, D. J., Rowley, N., Spence, A., Carter, H., Whyte, G., George, K., et al. (2013). Why isn't flow-mediated dilation enhanced in athletes? Med. Sci. Sports Exerc. 45, 75-82. doi: 10.1249/MSS.0b013e318269affe

Green, D. J., Spence, A., Halliwill, J. R., Cable, N. T., and Thijssen, D. H. (2011). Exercise and vascular adaptation in asymptomatic humans. Exp. Physiol. 96, 57-70. doi: 10.1113/expphysiol.2009.048694

Green, D. J., Spence, A., Rowley, N., Thijssen, D. H., and Naylor, L. H. (2012). Vascular adaptation in athletes: is there an 'athlete's artery'? Exp. Physiol. 97, 295-304. doi: 10.1113/expphysiol.2011.058826

Hagmar, M., Eriksson, M. J., Lindholm, C., Schenck-Gustafsson, K., and Hirschberg, A. L. (2006). Endothelial function in post-menopausal former elite athletes. Clin. J. Sport Med. 16, 247-252. doi: 10.1097/00042752-20060500000011

Hammouda, O., Chtourou, H., Chahed, H., Ferchichi, S., Chaouachi, A., Kallel, C., et al. (2012). High intensity exercise affects diurnal variation of some biological markers in trained subjects. Int. J. Sports Med. 33, 886-891. doi: 10.1055/s-0032-1301887

Haskell, W. L., Sims, C., Myll, J., Bortz, W. M., St Goar, F. G., and Alderman, E. L. (1993). Coronary artery size and dilating capacity in ultradistance runners. Circulation 87, 1076-1082. doi: 10.1161/01.CIR.87. 4.1076

Heinonen, I., Wendelin-Saarenhovi, M., Kaskinoro, K., Knuuti, J., Scheinin, M., and Kalliokoski, K. K. (2013). Inhibition of alpha-adrenergic tone disturbs the distribution of blood flow in the exercising human limb. Am. J. Physiol. Heart Circ. Physiol. 305, H163-H172. doi: 10.1152/ajpheart.00925.2012

Hellsten, Y., Nyberg, M., Jensen, L. G., and Mortensen, S. P. (2012). Vasodilator interactions in skeletal muscle blood flow regulation. J. Physiol. 590, 6297-6305. doi: 10.1113/jphysiol.2012.240762

Higashi, Y., Sasaki, S., Kurisu, S., Yoshimizu, A., Sasaki, N., Matsuura, H., et al. (1999). Regular aerobic exercise augments endothelium-dependent vascular relaxation in normotensive as well as hypertensive subjects: 
role of endothelium-derived nitric oxide. Circulation 100, 1194-1202. doi: 10.1161/01.CIR.100.11.1194

Ioannidis, J. P. (2005). Why most published research findings are false. PLoS Med. 2:e124. doi: 10.1371/journal.pmed.0020124

Jensen-Urstad, K., Bouvier, F., and Jensen-Urstad, M. (1999). Preserved vascular reactivity in elderly male athletes. Scand. J. Med. Sci. Sports 9, 88-91. doi: 10.1111/j.1600-0838.1999.tb00214.x

Joyner, M. J., and Green, D. J. (2009). Exercise protects the cardiovascular system: effects beyond traditional risk factors. J. Physiol. 587, 5551-5558. doi: 10.1113/jphysiol.2009.179432

Joyner, M. J., and Wilkins, B. W. (2007). Exercise hyperaemia: is anything obligatory but the hyperaemia? J. Physiol. 583, 855-860. doi: 10.1113/jphysiol.2007.135889

Kalliokoski, K. K., Oikonen, V., Takala, T. O., Sipila, H., Knuuti, J., and Nuutila, P. (2001). Enhanced oxygen extraction and reduced flow heterogeneity in exercising muscle in endurance-trained men. Am. J. Physiol. Endocrinol. Metab. 280, E1015-E1021.

Kasikcioglu, E., Oflaz, H., Kasikcioglu, H. A., Kayserilioglu, A., Umman, S., and Meric, M. (2005). Endothelial flow-mediated dilatation and exercise capacity in highly trained endurance athletes. Tohoku J. Exp. Med. 205, 45-51. doi: $10.1620 /$ tjem.205.45

Korthuis, R. J. (2011). Skeletal Muscle Circulation. San Rafael, CA: Morgan \& Claypool Life Sciences. doi: 10.4199/c00035ed1v01y201106isp023

Lawrenson, L., Hoff, J., and Richardson, R. S. (2004). Aging attenuates vascular and metabolic plasticity but does not limit improvement in muscle VO(2) max. Am. J. Physiol. Heart Circ. Physiol. 286, H1565-H1572. doi: 10.1152/ajpheart.01070.2003

Lloyd, P. G., Prior, B. M., Yang, H. T., and Terjung, R. L. (2003). Angiogenic growth factor expression in rat skeletal muscle in response to exercise training. Am. J. Physiol. Heart Circ. Physiol. 284, H1668-H1678. doi: 10.1152/ajpheart.00743.2002

Maiorana, A., O'driscoll, G., Taylor, R., and Green, D. (2003). Exercise and the nitric oxide vasodilator system. Sports Med. 33, 1013-1035. doi: 10.2165/00007256-200333140-00001

Moe, I. T., Hoven, H., Hetland, E. V., Rognmo, O., and Slordahl, S. A. (2005). Endothelial function in highly endurance-trained and sedentary, healthy young women. Vasc. Med. 10, 97-102. doi: 10.1191/1358863x05vm592oa

Mollard, P., Woorons, X., Letournel, M., Lamberto, C., Favret, F., Pichon, A., et al. (2007a). Determinant factors of the decrease in aerobic performance in moderate acute hypoxia in women endurance athletes. Respir. Physiol. Neurobiol. 159, 178-186. doi: 10.1016/j.resp.2007.06.012

Mollard, P., Woorons, X., Letournel, M., Lamberto, C., Favret, F., Pichon, A., et al. (2007b). Determinants of maximal oxygen uptake in moderate acute hypoxia in endurance athletes. Eur. J. Appl. Physiol. 100, 663-673. doi: 10.1007/s00421007-0457-0

Montero, D., Obert, P., and Walther, G. (2013). Enhanced conduit artery flowmediated dilation in elite athletes: false or reality? [corrected]. Med. Sci. Sports Exerc. 45:1219. doi: 10.1249/MSS.0b013e31828d5ffc

Montero, D., Padilla, J., Diaz-Canestro, C., Muris, D. M., Pyke, K. E., Obert, P., et al. (2014a). Flow-mediated dilation in athletes: influence of aging. Med. Sci. Sports Exerc. 46, 2148-2158. doi: 10.1249/MSS.0000000000 000341

Montero, D., Walther, G., Diaz-Canestro, C., Pyke, K. E., and Padilla, J. (2014b). Microvascular dilator function in athletes: a systematic review and meta-analysis. Med. Sci. Sports Exerc. doi: 10.1249/MSS.0000000000 000567. [Epub ahead of print].

Mortensen, S. P., Dawson, E. A., Yoshiga, C. C., Dalsgaard, M. K., Damsgaard, R., Secher, N. H., et al. (2005). Limitations to systemic and locomotor limb muscle oxygen delivery and uptake during maximal exercise in humans. J. Physiol. 566, 273-285. doi: 10.1113/jphysiol.2005.086025

Mortensen, S. P., Morkeberg, J., Thaning, P., Hellsten, Y., and Saltin, B. (2012). Two weeks of muscle immobilization impairs functional sympatholysis but increases exercise hyperemia and the vasodilatory responsiveness to infused ATP. Am. J. Physiol. Heart Circ. Physiol. 302, H2074-H2082. doi: 10.1152/ajpheart.01204.2011

Naylor, L. H., O'driscoll, G., Fitzsimons, M., Arnolda, L. F., and Green, D. J. (2006). Effects of training resumption on conduit arterial diameter in elite rowers. Med. Sci. Sports Exerc. 38, 86-92. doi: 10.1249/01.mss.0000181220.03855.1c
Nualnim, N., Barnes, J. N., Tarumi, T., Renzi, C. P., and Tanaka, H. (2011). Comparison of central artery elasticity in swimmers, runners, and the sedentary. Am. J. Cardiol. 107, 783-787. doi: 10.1016/j.amjcard.2010. 10.062

Oltman, C. L., Parker, J. L., Adams, H. R., and Laughlin, M. H. (1992). Effects of exercise training on vasomotor reactivity of porcine coronary arteries. Am. J. Physiol. 263, H372-H382.

Pagliaro, P., Senzaki, H., Paolocci, N., Isoda, T., Sunagawa, G., Recchia, F. A., et al. (1999). Specificity of synergistic coronary flow enhancement by adenosine and pulsatile perfusion in the dog. J. Physiol. 520(Pt 1), 271-280. doi: 10.1111/j.1469-7793.1999.00271.x

Phillips, S. A., Das, E., Wang, J., Pritchard, K., and Gutterman, D. D. (2011). Resistance and aerobic exercise protects against acute endothelial impairment induced by a single exposure to hypertension during exertion. J. Appl. Physiol. 110, 1013-1020. doi: 10.1152/japplphysiol.00438.2010

Prior, B. M., Lloyd, P. G., Ren, J., Li, Z., Yang, H. T., Laughlin, M. H., et al. (2003a). Arteriogenesis: role of nitric oxide. Endothelium 10, 207-216. doi: $10.1080 / 713715241$

Prior, B. M., Lloyd, P. G., Yang, H. T., and Terjung, R. L. (2003b). Exercise-induced vascular remodeling. Exerc. Sport Sci. Rev. 31, 26-33. doi: 10.1097/00003677200301000-00006

Proctor, D. N., Miller, J. D., Dietz, N. M., Minson, C. T., and Joyner, M. J. (2001). Reduced submaximal leg blood flow after high-intensity aerobic training. J. Appl. Physiol. (1985) 91, 2619-2627.

Pyke, K. E., and Tschakovsky, M. E. (2007). Peak vs. total reactive hyperemia: which determines the magnitude of flow-mediated dilation? J. Appl. Physiol. (1985) 102, 1510-1519. doi: 10.1152/japplphysiol.01024.2006

Rakobowchuk, M., Harris, E., Taylor, A., Baliga, V., Cubbon, R. M., Rossiter, H. B., et al. (2012). Heavy and moderate interval exercise training alters low-flow-mediated constriction but does not increase circulating progenitor cells in healthy humans. Exp. Physiol. 97, 375-385. doi: 10.1113/expphysiol.2011.062836

Reed, A. S., Tschakovsky, M. E., Minson, C. T., Halliwill, J. R., Torp, K. D., Nauss, L. A., et al. (2000). Skeletal muscle vasodilatation during sympathoexcitation is not neurally mediated in humans. J. Physiol. 525(Pt 1), 253-262. doi: 10.1111/j.1469-7793.2000.t01-1-00253.x

Rickenlund, A., Eriksson, M. J., Schenck-Gustafsson, K., and Hirschberg, A. L. (2005). Oral contraceptives improve endothelial function in amenorrheic athletes. J. Clin. Endocrinol. Metab. 90, 3162-3167. doi: 10.1210/jc.2004-1964

Ridout, S. J., Parker, B. A., and Proctor, D. N. (2005). Age and regional specificity of peak limb vascular conductance in women. J. Appl. Physiol. (1985) 99, 2067-2074. doi: 10.1152/japplphysiol.00825.2005

Rinder, M. R., Spina, R. J., and Ehsani, A. A. (2000). Enhanced endotheliumdependent vasodilation in older endurance-trained men. J Appl Physiol 88, 761-766.

Rognmo, O., Bjornstad, T. H., Kahrs, C., Tjonna, A. E., Bye, A., Haram, P. M., et al. (2008). Endothelial function in highly endurance-trained men: effects of acute exercise. J. Strength Cond. Res. 22, 535-542. doi: 10.1519/JSC.0b013e31816354b1

Rosenmeier, J. B., Hansen, J., and Gonzalez-Alonso, J. (2004). Circulating ATPinduced vasodilatation overrides sympathetic vasoconstrictor activity in human skeletal muscle. J. Physiol. 558, 351-365. doi: 10.1113/jphysiol.2004.063107

Rowley, N. J., Green, D. J., George, K., Thijssen, D. H. J., Oxborough, D., Sharma, S., et al. (2012). Peripheral vascular structure and function in hypertrophic cardiomyopathy. Br. J. Sports Med. 46, 98-103. doi: 10.1136/bjsports-2012091366

Rywik, T. M., Blackman, M. R., Yataco, A. R., Vaitkevicius, P. V., Zink, R. C., Cottrell, E. H., et al. (1999). Enhanced endothelial vasoreactivity in endurancetrained older men. J. Appl. Physiol. 87, 2136-2142.

Sugawara, J., Komine, H., Hayashi, K., Yoshizawa, M., Otsuki, T., Shimojo, N., et al. (2007). Systemic alpha-adrenergic and nitric oxide inhibition on basal limb blood flow: effects of endurance training in middle-aged and older adults. Am. J. Physiol. Heart Circ. Physiol. 293, H1466-H1472. doi: 10.1152/ajpheart.00273.2007

Tanriverdi, H., Evrengul, H., Tanriverdi, S., Turgut, S., Akdag, B., Kaftan, H. A., et al. (2005). Improved endothelium dependent vasodilation in endurance athletes and its relation with ACE I/D polymorphism. Circ. J. 69, 1105-1110. doi: $10.1253 /$ circj.69.1105 
Thijssen, D. H., Black, M. A., Pyke, K. E., Padilla, J., Atkinson, G., Harris, R. A., et al. (2011). Assessment of flow-mediated dilation in humans: a methodological and physiological guideline. Am. J. Physiol. Heart Circ. Physiol. 300, H2-H12. doi: 10.1152/ajpheart.00471.2010

Thijssen, D. H., Dawson, E. A., Black, M. A., Hopman, M. T., Cable, N. T., and Green, D. J. (2008). Heterogeneity in conduit artery function in humans: impact of arterial size. Am. J. Physiol. Heart Circ. Physiol. 295, H1927-H1934. doi: 10.1152/ajpheart.00405.2008

Tschakovsky, M. E., Sujirattanawimol, K., Ruble, S. B., Valic, Z., and Joyner, M. J. (2002). Is sympathetic neural vasoconstriction blunted in the vascular bed of exercising human muscle? J. Physiol. 541, 623-635. doi: 10.1113/jphysiol.2001.014431

Walther, G., Nottin, S., Karpoff, L., Perez-Martin, A., Dauzat, M., and Obert, P. (2008). Flow-mediated dilation and exercise-induced hyperaemia in highly trained athletes: comparison of the upper and lower limb vasculature. Acta Physiol. (Oxf). 193, 139-150. doi: 10.1111/j.1748-1716.2008. 01834.x
Welsch, M. A., Blalock, P., Credeur, D. P., and Parish, T. R. (2013). Comparison of brachial artery vasoreactivity in elite power athletes and age-matched controls. PLoS ONE 8:e54718. doi: 10.1371/journal.pone.0054718

Zoladz, J. A., Semik, D., Zawadowska, B., Majerczak, J., Karasinski, J., Kolodziejski, L., et al. (2005). Capillary density and capillary-to-fibre ratio in vastus lateralis muscle of untrained and trained men. Folia Histochem. Cytobiol. 43, 11-17.

Conflict of Interest Statement: The author declares that the research was conducted in the absence of any commercial or financial relationships that could be construed as a potential conflict of interest.

Copyright $\odot 2015$ Montero. This is an open-access article distributed under the terms of the Creative Commons Attribution License (CC BY). The use, distribution or reproduction in other forums is permitted, provided the original author(s) or licensor are credited and that the original publication in this journal is cited, in accordance with accepted academic practice. No use, distribution or reproduction is permitted which does not comply with these terms. 